\title{
The National Health Insurance Scheme an Alternative Source of Health Care Funding in Nigeria: A Case Study of Borno State
}

\author{
Artilce by Largema Bukar \\ Management, Texila American University \\ E-mail: largems2@gmail.com
}

\begin{abstract}
Introduction: In nearly every society, the standard of living is to a large extent determined by access to goods and services that fulfilled basic human needs. The qualities of a country's population, no doubt, enhance productivity, economic growth and development. The declined in Nigerian Government revenues since the wake of the economic crisis of the 1980's has necessitated cut in public expenditure including health which leads to increase in out-of-pocket (OOP) expenditure in health of average family. To reduce the OOP, the government introduces the National Health Insurance Scheme (NHIS) in Nigeria to compliment government and family's effort in health care financing.

Objectives: The paper aimed to look into the role of National Insurance Scheme as an alternative source of health care financing in Nigeria most particularly in Borno State.

Method: The research intents to galvanized the stakeholders in the state to understand the need to identify more opportunities for financing health especially with focus on to support the reduction of maternal and child mortality in the state.

Results: Stakeholders in the program states were made to understand that, financing health is not the sole responsibility of government or agencies but everyone business. There is the need to holistically support the implementation of the scheme in the state.

Conclusions: The emergence and success of the health insurance scheme as a means of co-financing health care in developed nation e.g. United Kingdom, China etc., and its attendant success propelled the developing nation like Nigeria to adopt the scheme with the view to finding lasting solutions to its peculiar high health indices/ care problems and there is the need to have the enabling policy environment for the full benefit of the scheme.
\end{abstract}

Keywords for indexing: Northern Nigeria, Borno state, National Health Insurance scheme, health financing, out-of-pocket expenses, stakeholders, service providers, utilization, maternal mortality rate, child mortality rate.

\section{Introduction}

Borno state is one of the 37 states in Nigeria, located at the far northern Nigeria with a population density of 5.8million largely agrarian and $77 \%$ below poverty level. The state is one of the highest in terms of disease burden with maternal mortality rate (MMR) of 1,538/100,000 and child mortality rate (CMR) of 160/1,000 population.

Nigeria is one of the countries in the world with a high out-of-pocket expenditure in health. It is estimated that over $75 \%-80 \%$ of medical expenses are bound by the patient while government is only responsible for between $10 \%-15 \%$ and this over stretched the meager family income which is about 1.9 dollar per day.

In nearly every society, the standard of living is to a large extent determined by access to goods and services that fulfilled basic human needs. The qualities of a country's population, no doubt, enhance productivity and economic growth and development. This is mainly because a healthy and well-fed labor force is more capable of greater physical and mental exertion than one that is ill, hungry and mal-nourished and declined in government revenue since the wake of the economic crisis of the 1980's has necessitated cut in public expenditure including expenditure on health. 
In Nigeria, in spite of the resource constrain, government seems committed to improving health care delivery in the country and the National Insurance Scheme (NHIS) is one of the government efforts in this regard.

Health is a very important aspect of an individual's wellbeing, and since individuals make a nation, therefore, healthcare could be regarded as one of the necessary conditions to achieving a sustainable longterm economic development. "Health can be defined to mean general physical condition i.e. condition of the body or mind especially in terms of the presence or absence of illness, injuries or impairments" (Sule, 1995). The issue of health is a very sensitive one because it deals with not just humans but with human body. Without a good health condition, it is almost impossible to carry out any economic activity and if at all there is any it will certainly not be efficient and so we really have to take this subject seriously (Cremieux, et al., 1999).

It has been established in the literature that improvement in health care is an important prerequisite for enhancing Human Capital Development (HCD) in any and every economy. According to Siddiqui, Afridi and Haq (1995), they opined that improved health status of a nation creates outward shift in labour supply curve/increase productivity of labour with a resultant increase in productivity of investment in other forms of human capital. Thus, the level of government expenditure on health determines the ultimate level of human capital development which eventually leads to better, more skillful, efficient and productive investment in other sector of the economy (Muhammad and Khan, 2007).

The financial commitments of government to the health sector are both the recurrent and capital expenditure on health. The capital expenditure of government decreases from N7.3million in 1970 to N4.88 million in 1972 before it rose again to N126.75 in 1994. It dropped sharply to N79.2 million in 1982. From 1982 to 1987, capital expenditure on health declined from N72.9m in 1982 to an all-time low of N17.2m in 1987. This development is occasioned by the fact government was more preoccupied in the business of paying workers' salaries with less attention being paid to capital expenditure. In 1988 there was a significant rise to N297.96m. By 1991, the statistic dropped to N137.3m but plummeted to N33.72m in 1992. The figure rose steadily from N586.2 million in 1993 to N17,717.42m, N33,396.97m and N34,647.9m in 2003, 2005 and 2007 respectively the capital expenditure on health stood at N64,922.9m in 2008 and N79,321.09m in 2011.

The recurrent expenditure on health also follows a similar trend. It rose gradually from N12.48m in 1970 to $\mathrm{N} 59.47 \mathrm{~m}$ in 1977 but fell to $\mathrm{N} 40.48 \mathrm{~m}$ in the successive year. The pattern of health expenditure at this period is a reflection of both the product of the disposition of government policy towards health issue and the determination of the Federal Government to improve the health care system with the wind fall of oil revenue. Recurrent expenditure nosedived into N15.32 m in 1979 before it rose to N52.79m, N84.46m N82.79 million in 1979, 1987 and 1983 respectively. From 1984 to 1986, recurrent expenditure rose from N101.55m to $\mathrm{N} 134.12 \mathrm{~m}$ when the recurrent expenditure as a percentage of total expenditure stood at 77.4 percent. The value of recurrent health expenditure reduced significantly in 1987 to $\mathrm{N} 41.31 \mathrm{~m}$ before it rose steadily from $\mathrm{N} 422.80$ in 1988 to $\mathrm{N} 24,522.27 \mathrm{~m}$ in 2001. This figure rose again from N40,621.42 in 2002 to N44,551.63, N58,686.56 and N72,290.07 in 2005, 2006 and 2007 respectively.

\section{Literature reviews}

Insurance was defined by (Boateng, 1981), "as a system whereby compensation can be paid for losses". All those people who are in a position to suffer a loss or losses and who participate in the scheme by contributing to it, have the right to claim from the fund, should the event insure against occurs. It is often referred to as the "pooling of risks".

Health Insurance is a policy instrument designed by federal government to improve the health status of all Nigerians at cheaper cost by spreading the risk and creating appropriate incentive to consumers of health services (Emenuga, 1996).

\section{The scope of the national health insurance scheme}

The scope of the scheme should be considered in two ways (EDOZIEN, 1995).

1. The benefits 
2. The coverage i.e. the population to be covered.

Benefits: As proposed by the ERONINI committee in 1988 and approved by the Federal Ministry of Health, were presented to the Federal Executive Council in 1989, the Council examined the guidelines provided by the International actuary, UNDP/ILO in 1992 which were:

A: Curative care by a private Doctor or by a Doctor in the government service, including drugs and diagnostic tests.

B: Preventive care:

C: Maternity care, including pre-natal, confinement and post-natal care either by medical practitioners or by qualified midwives and hospitalization, where necessary.

D Consultation with specialist

E. Hospital cares in public or private hospitals in a standard ward for physical or chronic psychiatric illness.

F. Eye examination as a part of general medical care but excluding tests for the provisions of spectacles.

G: Prescribed range of prostheses.

H: Some limited dental care. (Culled EDOZIEN, 1995).

Coverage: Though the scheme is national in scope and, according to the constitution must not differentiate against a citizen, for the purpose of the insurance and collection of contribution, the group are divided into two, compulsory and voluntary groups: -

1. Compulsory group: -

A. civil servant

B. employees of parastatals and statutory bodies

C. Private firms or institutions with more than ten employees, i.e all those covered by Nigerian Social Insurance Trust Fund (NSITF)

\section{Types of health insurance scheme}

1. The direct system: - In this type, the health insurance authority owns the facilities and allows the insured avail themselves of the service assured.

2. The indirect system: - Is a system where insurance authority does not own any facility's, fully contracts with providers who received payment from the authority rather than from the insured when health services are provided. The Nigerian Insurance scheme is built on the indirect system (EDOZIEN, 1995).

Basically, the National health insurance Scheme (NHIS) is aimed at providing the opportunity to achieve the following goals-

(a) To ensure that every Nigerian have access to health care services at an affordable cost.

(b) To protect families from the financial hardship of huge medical bills.

(c) To limit the rise in cost of health care services.

(d) To distribute health care cost equitably among different income groups.

(e) To set and monitor standards of health care delivery services.

(f) To eventually cover the whole nation, and for efficient health care services.

(g) To establish a health care system that adapts easily to local conditions and changing technology.

(h) To redress the imbalance between curative and preventive medicine, on one hand, and the distribution of health institution on the other hand.

(i) To provide infrastructure facilities for all preventive health care programmes with all the above goals, it is pertinent to recall past and present event which could have been subverted had the national health insurance scheme been put in place in Nigeria.

a) Present overseas medical expenses can be reducing on the basis of linkage and association: the NHIS can develop with other friendly countries with similar scheme. This means the NHIS can utilize the services of some health institutions outside the county at a less expense.

b) Costing for accurate health budget will be made easier, dependable and more accurate from the data, which will be available through the operation of the NHIS. This could enable the government to easily reach a 
DOI: 10.21522/TIJMG.2015.SE.19.01.Art003

ISSN: 2520-310X

decision on subsidies and with more funds at their disposal for curative health care. It would enable them devote more resources to other sectors which are full responsibilities of the government and hence improve the quality of health care to the population through availability of funds.

\section{Theoretical framework}

This section is concern with reviewing the theory as put forward by scholars, which we will use as a framework within which we based our observation and research. The theoretical basis, which we will use in this research, is the collaborative practice model.

\section{Collaborative practice model}

This model is centered on the relationship of the National Health Insurance Council, the State Board, the health maintenance organization, private health insurance organizations, health providers and more importantly the patient, and how this tri-angulation or relationship enhance or hinders the care provided to the patient or his family.

The collaborative practice model was defined as "the joint determination of relationship among members of the health care team, whose sole purpose is to integrate their care practice into a comprehensive approach to meet the needs of patients and families" (Jeffrey, 1970).

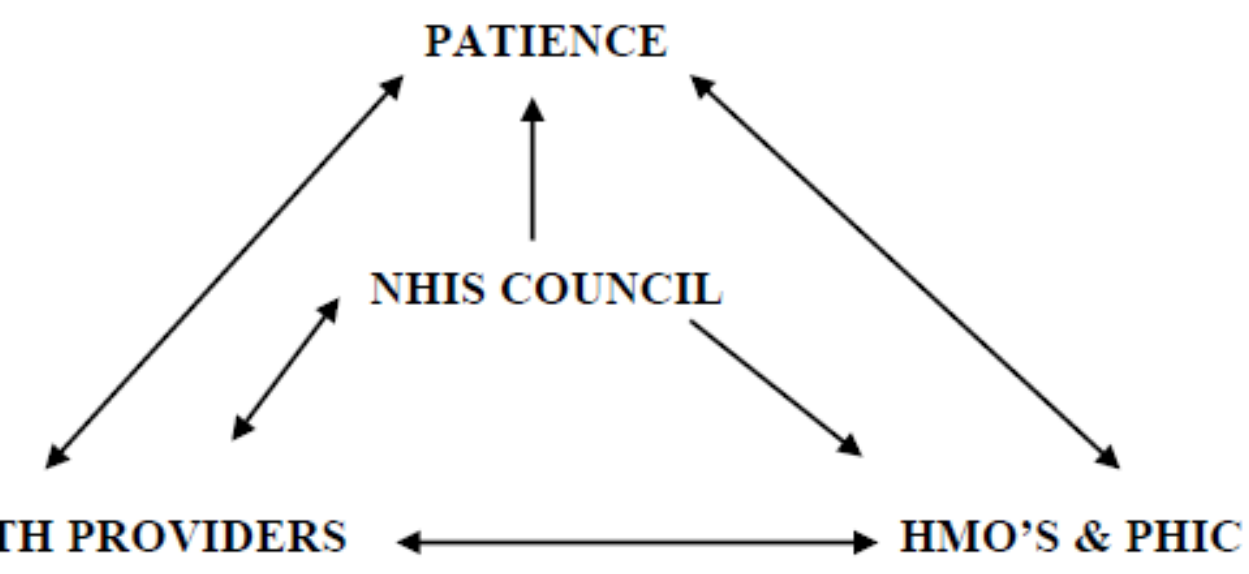

\section{HEALTH PROVIDERS}

The collaborative practice model sketch

The above sketch means that the relationship is mutual; it includes a co-operative venture between the health consumers, the Health insurance council and the state board, and other bodies engaged in effective coverage of the scheme that is the Health maintenance organization, Insurance Corporation and health providers. There is much discussion and communication among the health insurance team to provide care in an integrated, interactive and comprehensive manner. Thus, ensuring a higher quality of patient care because of shared decision making, evaluation of care in an ongoing manner and incorporates feed-backs from all participants is encouraged so that care can be adopted and ultimately the needs of the patient can be served more efficiently and effectively.

The end results of this model are that, all team members share in controlling cost and mal-practices. The ultimate gain of this model is improved patients and health care coverage.

This paper is based on the research work conducted which is aimed at understanding the prospects and problems of the scheme and proffer solution with regard to the problems identified for a successful implementation of the scheme in the state.

\section{Statement of problem}


The emergence and success of the health insurance scheme as a means of co-financing health care in developed nation e.g. United Kingdom, China etc. and its attendant success propelled the developing nation especially Nigeria to adopt the scheme with the view to finding lasting solutions to its peculiar health care problems.

The Nigeria nation since independence has been battling with the problems of health care provision to the Nigerian people. However, due to vast nature of the Nigerian State, couples with low level of education, which is indicated in the under-utilization of the 14,530 health care institutions throughout Nigeria (Health census, 1993). The emphasis on curative health care services to the population as characterized by the proliferation of health institutions and the placement of emphasis on the training of curative personnel e.g. Doctors, Nurses etc. at the expense of the preventive health care e.g. less emphasis place on the training of community physicians, community and public health workers all indicate a signal to the low attention accorded the preventive health care outfit and this leads to more money vested on the maintenance, refurbishment of equipment, facilities and hence more financial problems.

The primary health care (PHC) component emphasized collaborative teamwork among the various socioeconomic facets of our society e.g. Agriculture, water supply, education etc. But, in Nigeria, the PHC concept received little or no attention from the implementers of the programme as such there is lack of operational linkages of the various components of the primary health care delivery system. (Shehu, 1995)

However, efforts of the government to improve the health care financing have been not encouraging, most especially with the adoption of the "Abuja Declaration" of allocating at-least $15 \%$ of the nation annual budget to health sector as adopted by the African, and also the adoption of primary health care approach. But all these yielded little improvement in the health sector, the institutionalization of the health insurance scheme to health care, where the populace co-finances health care with a view to improving greatly the quality of health care services.

\section{Objectives of the study}

The objective of the study is

1. To examine the evolution of the National Health Insurance scheme Nigeria.

2. To assess the level of implementation of the National Health Insurance scheme in Nigeria.

3. To identify the major obstacles hindering the National Health Insurance scheme in Nigeria.

4. To proffer solution to those problems through recommendations of concrete policy options.

\section{Methodology}

This session is aimed at identifying the methods used for the collection of data, the type of respondent, and methods of data analysis. The sources for obtaining data for this research work are through questionnaire administration, which is using stratified and simple random method.

The population understudy was made up of the health professionals and personnel who are the health providers under the scheme which include, the Doctors, Nurses, Lab, Technicians, Health planners and administrators etc. and also the beneficiaries of the scheme are served with the questionnaire.

Stratified random sample method was used for the Health personnel i.e. Doctors, Nurses, pharmacist, administrator's etc. while simple random method were used for the contributors of the scheme (employers and employees). The selection criterion for the employers and employees was based on literacy and those that have been to the Hospital for treatment.

\section{Data analysis and presentation of findings}

The analysis presented in this session were the results of the completed questionnaires by the health professionals that is the Doctors, Nurses, Health Administration etc. and the responses from the general public (those who benefit from the services).

Thirty-five questionnaires were distributed among the health care professionals and out of it thirty completed questionnaires were return signifying $85.7 \%$ response, while a total of twenty questionnaires were 
DOI: 10.21522/TIJMG.2015.SE.19.01.Art003

ISSN: 2520-310X

distributed to the public (Health care beneficiaries) and a total of sixteen completed forms were returned, indicating $80 \%$ responses.

Relevant information derived from the questionnaires was used in the analysis. In order to substantiate the information gathered from the respondent, frequency distribution and percentage used for the analysis.

\section{Chart 1: Profession Background of respondents}

Question: What is your profession?

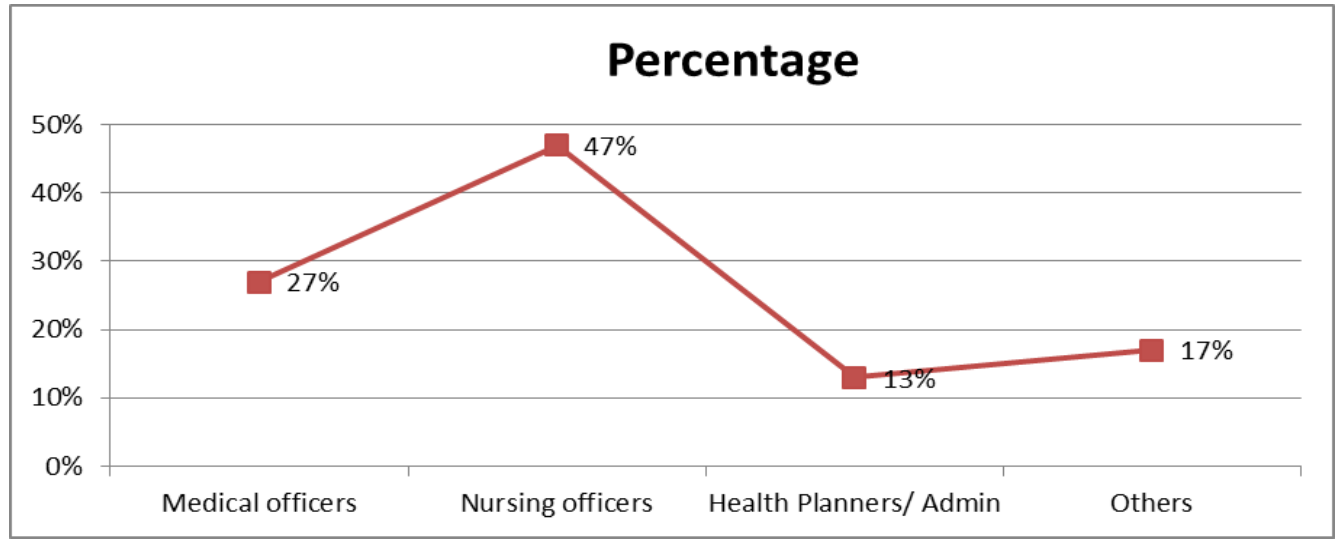

\section{Presentation}

This table sought to find the number of respondents within the health care professionals and administrators, $27 \%$ are medical Doctors, $43 \%$ are Nursing officers, $13 \%$ were Health Administrators and planners, while $17 \%$ are other cadres e.g. laboratory Technicians, Physiotherapist, Dieticians etc.

\section{Chart 2: Respondent's knowledge of what Health Insurance is}

Question: What is health Insurance all about?

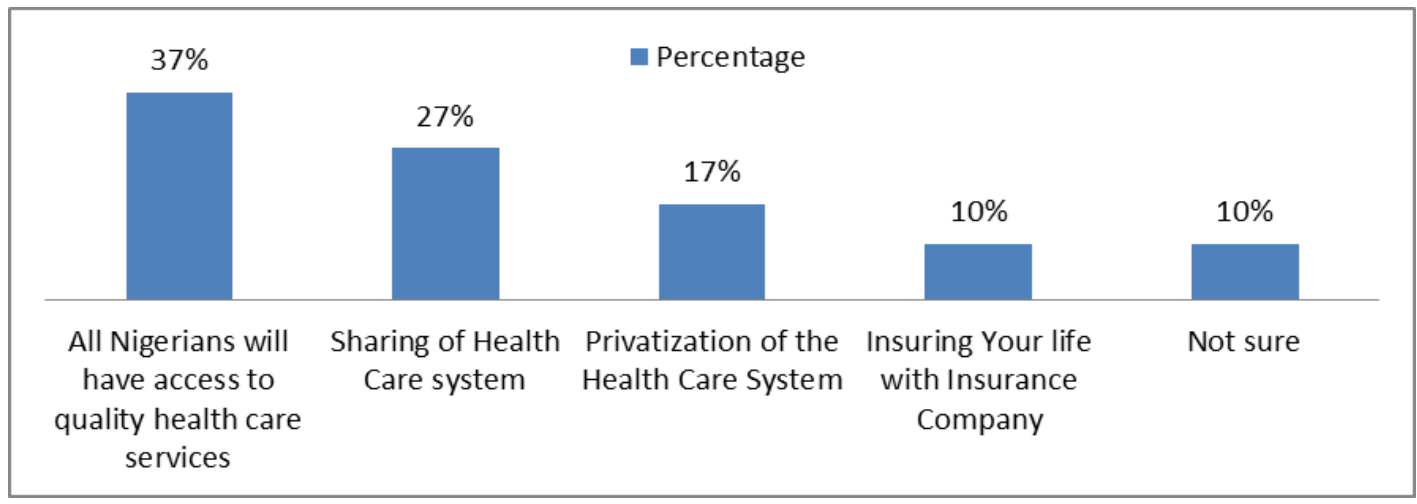

\section{Presentation}

From the question, 37\% of the respondents say that health insurance is about. All Nigerians having access to quality health care services; $27 \%$ say it's about sharing of health care cost among the contributors to the fund and $17 \%$ are of the opinion that health insurance is about insuring one's life with an insurance company and $10 \%$ say that they are not sure of what Health Insurance Scheme is all about.

\section{Chart 3: Respondent's knowledge of what is the objective of the National Health Insurance}

Question: What is the objective of the scheme? 


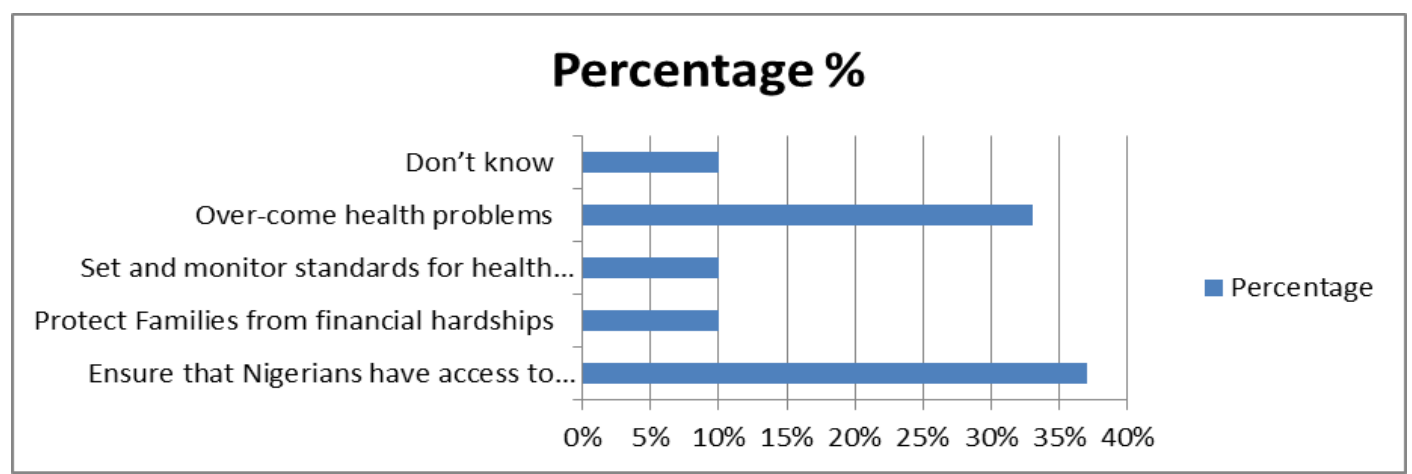

\section{Presentation}

This sought to find out the objective of the scheme. $37 \%$ of the opinion that the Health Insurance scheme is a means of insuring that Nigerians will have access to quality health care services, $10 \%$ say it will protect families from financial burden and $10 \%$ are of the view that it's about setting and monitoring standards for health care services in Nigeria. While 33\% say Health, insurance is about overcoming the health care problems and $10 \%$ say they don't know the objective of the scheme.

\section{Chart 4: Knowledge of Respondents of whether the objective is achievable}

Question: Do you think the objective is achievable?

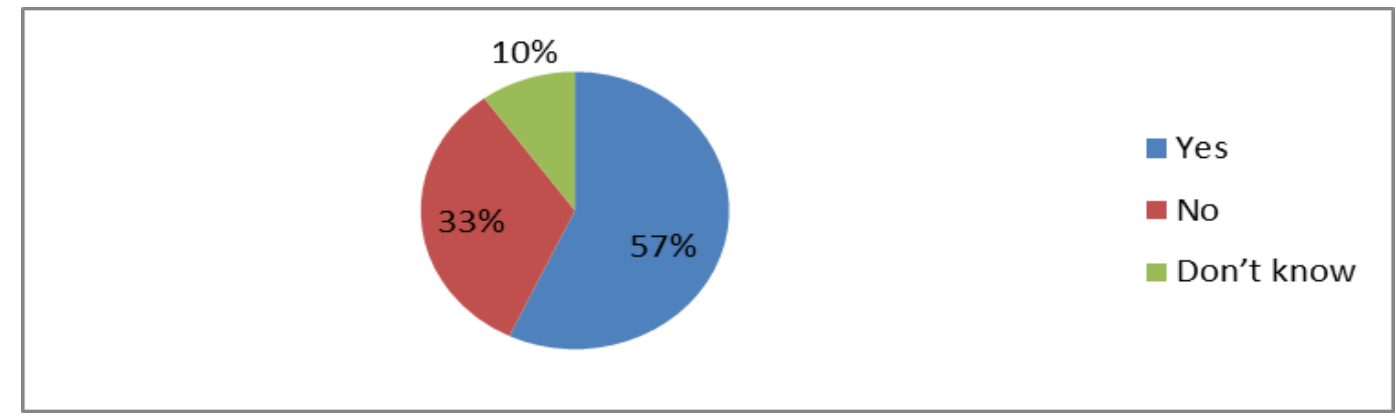

\section{Presentation}

This seeks to find out from the respondents whether the objective of health insurance in Nigeria is attainable or not, $57 \%$ say yes, it is attainable and $33 \%$ are of the view that the objectives is not attainable while $10 \%$ say they don't know. From the statistics one would understand that majority of the respondents are optimistic about the scheme.

\section{Chart 5: Respondent's knowledge of how to source for fund}

Question: Do you think the contribution should be compulsory and why?

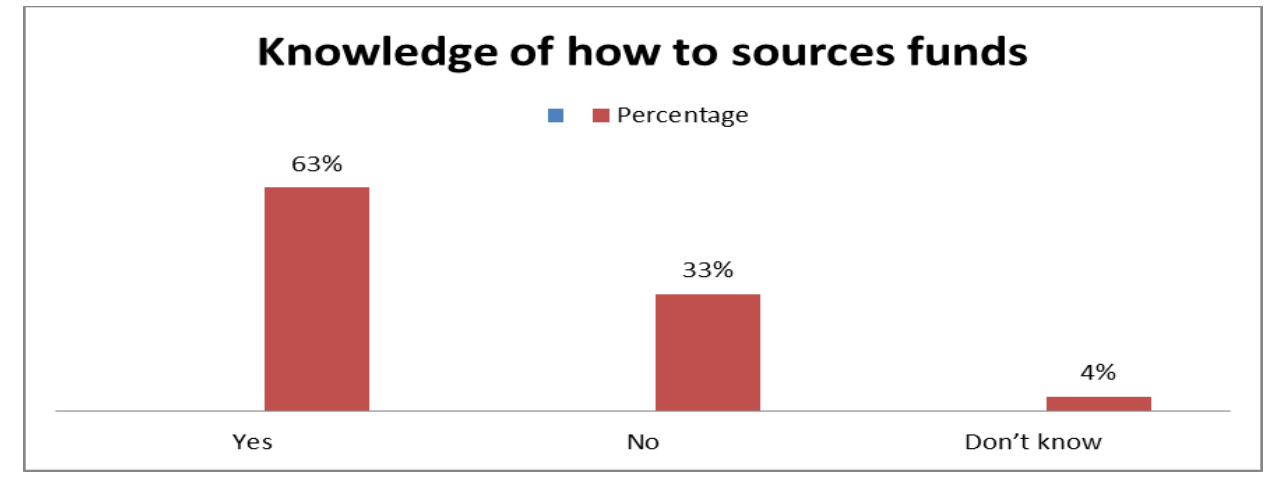


DOI: 10.21522/TIJMG.2015.SE.19.01.Art003

ISSN: 2520-310X

\section{Presentation}

This table tried to find out whether the contribution to the find be compulsory or not and why? $63 \%$ of the respondents say the contribution should be made compulsory for the following reasons:

a) Most Nigerian can't settle their medical bills on their own.

b) For full implementation of the health insurance scheme.

c) For the betterment of the general public with regard to their health.

While $33 \%$ of the respondents say the contribution should not be compulsory because of the following reasons:

a) May lead to poor implementation of the scheme.

b) The scheme may be faced with the problem of Nigerian factor i.e. failure of all government projects and programs.

c) Most people and organizations have their personal Health care facilities.

d) And only $4 \%$ of the respondents are uncertain of whether the contribution should be compulsory or not.

\section{Chart 6: Respondent's idea on the obstacle to the success of the scheme}

Question: What are the expected problems of the National Health Insurance Scheme?
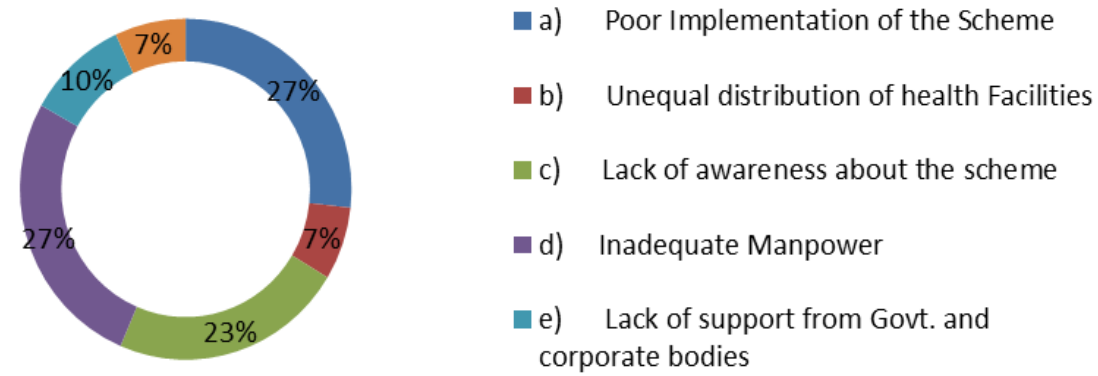

a) Poor Implementation of the Scheme

a) Unequal distribution of health Facilities

c) Lack of awareness about the scheme

d) Inadequate Manpower

ne) Lack of support from Govt. and corporate bodies

\section{Presentation}

This section is trying to find out the expected problems of the insurance scheme. $27 \%$ say they expect poor implementation of the scheme become Nigerian factor, $7 \%$ anticipated unequal distribution of the health care facilities; $23 \%$ say the expected problem is from lack of awareness about the scheme, while $27 \%$ say the problem could be as a result of inadequate manpower to manner the scheme, and $10 \%$ say the problem could be from lack of support from government and corporate bodies. And 7\% are not sure of the expected problems of the scheme.

\section{Discussion of the results/ findings}

As a generic, one could easily identify the following as the most basic problems facing the healthcare industry in Nigeria and Borno in particular.

a) Inability to replenish stocks

b) Lack of equipment

c) Inability to pay wages

d) Inability of government and private initiative to expand services to rural areas

e) Ineffective managerial systems.

It is generally known that the above problems cannot be solved without adequate funds. The government revenue most especially in the $20^{\text {th }}$ century is dwindling so much that the government cannot provide the huge amount required by the sector alone and hence the public participation in their health and subsequently the institutionalization of the national health insurance scheme to source for the extra capital required. 
It is a known fact that the National Health Insurance Scheme was adopted by the Government to make health care accessible and affordable to the people by pooling of resources from both the government and the general public and hence the establishment of the scheme to take care of the objective.

It is as a result the above that the researcher takes the pain and the cost asking the health providers and the general public on their perception, the anticipated problems of the scheme and the solution to smooth implementation of the scheme.

From the outcome of this session, the researcher was able to identify the following as the problems facing the National Insurance scheme in Nigeria and Borno in Particular.

a) Lack of proper implementation and supervision of the scheme

b) Inadequate manpower and finances

c) Lack of support by government and other bodies and organizations

d) Lack of trained and experienced personnel.

In view of the problems enunciated above the following suggestions were required from the respondents;

a) Adequate funds made available to the scheme

b) There should be legislation giving a legal backing to the scheme with immediate effects.

c) Publicity and enlightenment campaign should be identified

d) There should be proper supervision of the scheme outfit to ensure compliance to laid down rules and regulations.

e) There should be equitable distribution of health institutions and replenishment of stock.

In conclusion, it is the view of the researcher that once their solutions are implementation to the later, there would be successful health insurance practice in Borno State and Nigeria in General.

\section{Recommendations}

The National health Insurance scheme is a scheme fashioned out by the Federal government among others thing to reduce the financial burden of the populace in receiving medical treatment thereby making medical service easily accessible and also as a means of providing additional funds to the government improving the health facilities in Borno and the nation at large.

It is the view of the researcher from the data analyzed that the following suggestions will enhance the performance of the scheme and bring about wider acceptability and the attainment of its of its overall objective:

a) More publicity about the intent and purposes of the scheme to the health care providers and the contributors of funds to scheme.

b) Proper, timely implementation of and supervision of the all the outfits established in implementation process i.e. the state health insurance office, the health maintenance organization, private health insurance companies by the National insurance council.

c) There should be adequate training of personnel both the scheme officials and the health care providers and if possible, the employers and the employees who contributed fund to the scheme on the intricacies and the procedures of enjoying your contribution.

d) The entire scheme revolved around adequate finances, as such the government should not leave the funding entirely to the public, but should partake in co-financing the scheme, thereby reducing the financial burden on the public, since reducing health care cost is the objective of the scheme.

e) The government should as a matter of urgency promulgate an enabling decree to give a legal backing to the scheme in order to take up fully, and the government should compel corporate organizations and bodies to join the scheme.

f) The national health insurance council shall as a matter of seriousness ensure that the following does not occur in the discharge or performance of the scheme, as it would seriously sabotage the performance of the scheme. As such there should be proper legislation on those are:

i. Provider manipulation (is a situation where doctors and other health providers manipulate visits and bills in such a manner that their premium is increased). 
DOI: 10.21522/TIJMG.2015.SE.19.01.Art003

ISSN: 2520-310X

ii. The insured collecting with providers to over use services. (it's situation where workers are being given money to sign attendance so that the health providers could claim more money for services not done).

iii. Insurer abdication or illiquidity. (It's a situation where the Insurance companies faced the problems of cost over run and have failed to settled providers claims promptly).

In conclusion, the researcher is of the candid belief that, if these recommendations are fully implemented to the core, the National Health Insurance Scheme is a sure way of alternative sourcing of health care funding in Nigeria.

\section{References}

[1].Ajala O. V Mrs (1996): Scholarly writing guide for researchers Maybset Publishers; first Edition

[2].Anukwesi N. (1997): Thisday Newspapers "Experts hails NHIS" $14^{\text {th }}$ Nov. 1997.

[3].Checkoway B. Ed (1981): Citizens and health care, participation and planning for social change. Pergamon press Inc.

[4].Dlakwa H. (1997): Lecture Notes on public policy analysis; University of Maiduguri.

[5].El-Yakub K. Mrs (1998): Lecture notes of public policy and legal aspects of health care management. University of Maiduguri.

[6].Effah S. (1997): Lecture notes on qualitative research method University of Maiduguri

[7].Emenuga C. (1998): Seminar paper "Economics of scale as a tool for placing the establishment of the NHIS in Nigeria." Lagos.

[8].Edozien U.F. (1995): Seminar Paper "National Health Insurance Scheme, the alternative funding system for the health sector." Lagos.

[9].Erionosho L. Ed (1996): Nigerian Journal of health planning and management NJHPM Vol. 1, No 2 July - December 1996.

[10]. Fromer J. M. (1979): Community health and the Nursing process C.V Morby Company publishers, first Edition.

[11]. F.M.O.H Legal Unit (1996): Seminar paper "contract between NHIS, HMOs and PHIC Lagos.

[12]. F.M.O.H. (1988): National Health policy and strategy to achieve health for all Nigerian.

[13]. F.M.O.H. (1996): Pamphlet in National Health Insurance Scheme in Nigeria. Lagos.

[14]. Okpaise R. (1996): Seminar paper "Cost implication of various providers, payment systems in the health insurance scheme" Maiduguri.

[15]. Okorosobo T. (1996): Seminar paper "monitoring indices for adequate evaluation of the operation of the NHIS". Maiduguri.

[16]. Onukwesi N. (1996): Seminar paper utilizing HMOs and PHIC by NHIS to provide universal health coverage in Nigeria". Lagos.

[17]. Offiong O.D (1998): Imperialism and dependency, obstacle to African development. Fourth Dimension Publishers; $1^{\text {st }}$ Edition.

[18]. Shehu U. (1996): Seminar paper "health policies in Nigeria, an overview. Abuja Health submit. Abuja. 